\title{
Reducing health disparities in adult vision loss via interfaces with emerging technology
}

\author{
Juan S. Peña ${ }^{1} \cdot$ Maribel Vazquez $^{2}$
}

Received: 5 November 2018 / Accepted: 19 November 2018 / Published online: 5 December 2018

(c) The Royal College of Ophthalmologists 2018

Progressive vision loss affects growing numbers of adults by the age of 65 . Age-related loss of vision has become a key contributor to escalating health care expenditures per capita in nations that report increased longevity. Numbers of visually-impaired persons have increased steadily across the globe and will reach an unprecedented 25 Million in the United States (US) by the year 2050 [1]. Further, increases in health care costs consume rising portions of national gross domestic products (GDP) and have exceeded the current rate of GDP growth in the US, as shown in Fig. 1.

Health disparities (HD) in vision loss have also broadened worldwide to foreshadow multifaceted challenges for eye care. HD are defined as preventable differences in the incidence, prevalence and burden of vision loss on communities targeted by non-genetic factors, such as age, gender, ethnicity and geography. Interpreting the nature and origins of ocular HD is critical, as comprehensive analyses can yield meaningful impact in health care policy and/or reveal unexplored instigators of vision loss. For example, epigenetics are now well-accepted to impact disease progression and presentation through combinations of environmental factors, such as chronic stress and chemical exposure [2]. By contrast, higher incidence of adult vision loss reported among Americans in particular geographic regions remains unexplained [1], even when accounting for HD differences in health care coverage and access, as illustrated in Fig. 2a.

Disparities in vision are particularly complex because progressive loss may arise from different ocular

Maribel Vazquez

maribel.vazquez@rutgers.edu

1 Department of Biomedical Engineering, The City College of New York, New York, USA

2 Department of Biomedical Engineering, Rutgers, The State University of New Jersey, New Jersey, USA components and appears to target communities disproportionately. As shown in Fig. 2b, US vision loss from corneal disease impacts Asian-Americans at larger rates [1], whereas retinopathies such as macular degeneration and glaucoma are diagnosed at higher ratios in CaucasianAmerican males and African-American females, respectively [3]. Similarly, disorders of the lens, such as cataracts, adversely present in Hispanic-American women, while choroidal dystrophies disproportionately affect AfricanAmerican men [1,3].

Although multiple public health initiatives have promoted HD awareness [2], steadily-rising levels of HD herald a need for expanded HD research foci at interfaces between clinical medicine and emerging technology. HD in vision loss may be greatly reduced through synergies with biomaterials, nanoscience and microtechnologies to predict and validate changes in biological responses from a range of healthy and pathological tissues. Dissimilarities in cell and tissue responses to contemporary therapies can be predicted and examined using controlled, experimental models engineered by these technologies [4]. Further, emerging systems can be applied to elucidate epigenetic-induced pathologies in the visual system, as well as to deconstruct contributions to vision loss triggered by epigenetic changes in other physiological systems, such as cardiovascular or neurology. Lastly, the integration of technology with ocular HD has unique appeal to future cohorts of researchers and clinicians, as today's passion for social justice, equity and activism has promoted innovative technological solutions to a variety of community-based health challenges [5]. Such enthusiasm will help diffuse the unfortunate stigma that often surrounds HD and drive the evolution of ocular HD into a comprehensive, scientific discipline able to eliminate preventable vision loss in our lifetime. 
Fig. 1 Health care expenditures in the United States per capita from 2010-2016, as available from the US Center for Medicare and Medicaid Services. Inset: Rate of change $(\%)$ in US health care expenditures against rate of change (\%) of US gross domestic product (GDP) from 2010 to 2015.

Fig. 2 Health disparities in adult vision loss across the contiguous United States. a Distribution of predicted adult vision loss per capita in different geographical regions. Darkened areas represent states with highest average numbers of visuallyimpaired adults [1]. b Summary of American communities unduly affected by prevalent eye disorders alongside current therapies and technologies used for treatment.
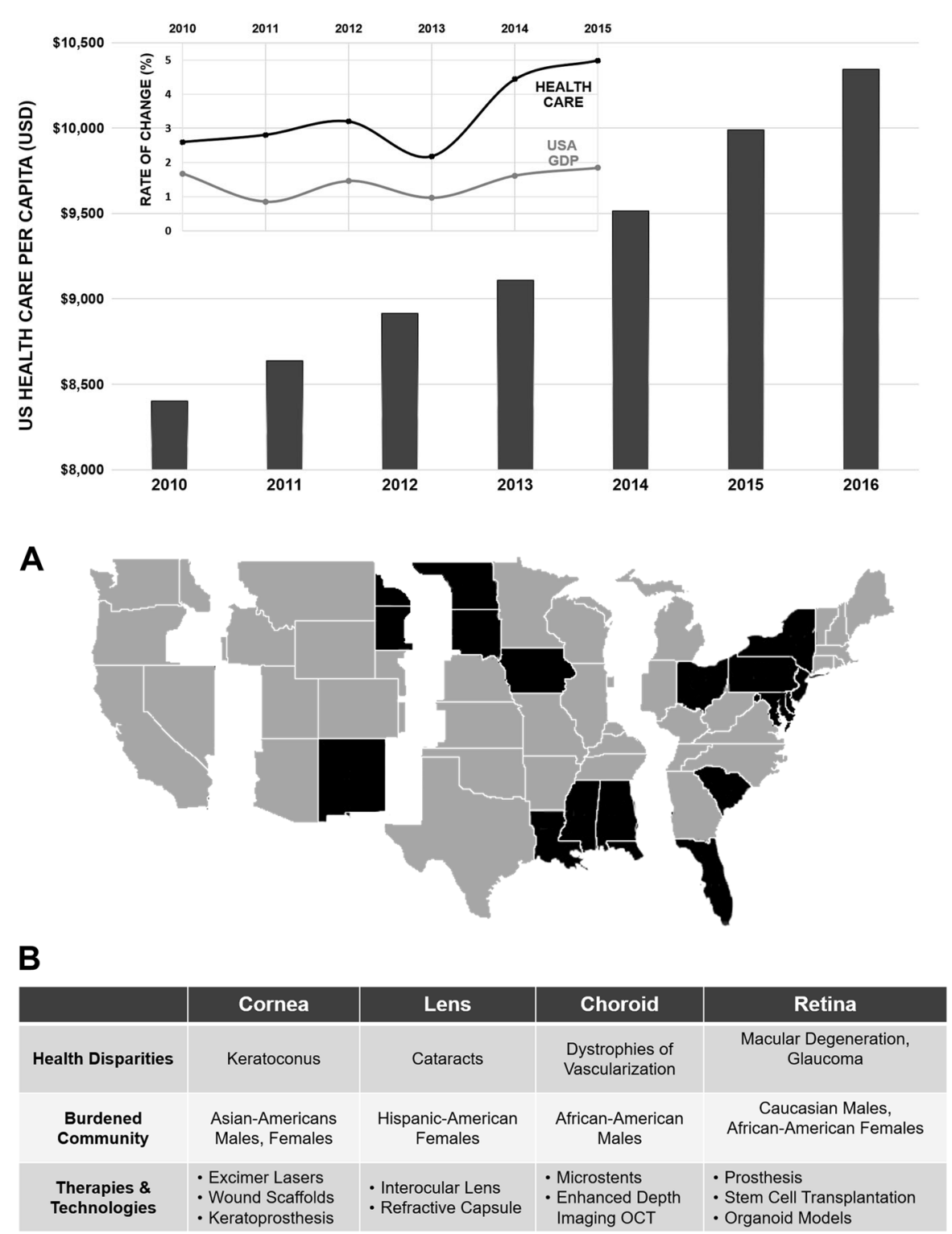

Funding: This work was supported by the National Institutes of Health (R21EY026752, U54CA132379) and National Science Foundation (CBET 0939511) of the United States.

\section{Compliance with ethical standards}

Conflict of interest The authors declare that they have no conflict of interest.

\section{References}

1. Varma R, Vajaranant TS, Burkemper B, Wu S, Torres M, Hsu C, Choudhury F, McKean-Cowdin R. Visual impairment and blindness in adults in the United States: demographic and geographic variations from 2015 to 2050. JAMA Ophthalmol. 2016;134:802-9.

2. Dankwa-Mullan I, Maddox YT. Embarking on a science vision for health disparities research. Am J Public Health. 2015;105(Suppl 3): S369-71.

3. Zhang X, Cotch MF, Ryskulova A, Primo SA, Nair P, Chou CF, Geiss LS, Barker LE, Elliott AF, Crews JE, Saaddine JB. Vision health disparities in the United States by race/ethnicity, education, and economic status: findings from two nationally representative surveys. Am J Ophthalmol. 2012;154(6 Suppl):S53-62. e1

4. Bobba S, Di Girolamo N, Munsie M, Chen F, Pebay A, Harkin D, Hewitt AW, O'Connor M, McLenachan S, Shadforth AMA, Watson SL. The current state of stem cell therapy for ocular disease. Exp Eye Res. 2018;177:65-75.

5. Vazquez M, Marte O, Barba J, Hubbard K. An approach to integrating health disparities within undergraduate biomedical engineering education. Ann Biomed Eng. 2017;45:2703-15. 